\title{
ANÁLISE DE CUSTOS E RESULTADOS POR MEIO DO MÉTODO ABC EM UM ESCRITÓRIO CONTÁBIL
}

\author{
Leonardo Thiago da Silva Ferreira ${ }^{1}$ \\ Leandro Franz ${ }^{2}$
}

\begin{abstract}
RESUMO
Este estudo tem como objetivos estudar e analisar os custos e receitas com a aplicação do método de custeio baseado em atividades (ABC) e apresentar o total dos custos de cada cliente da empresa contábil prestadora de serviços em Lucas do Rio Verde com quadro de 92 clientes dos regimes tributários do Simples Nacional, Lucro Real e Lucro Presumido, utilizando como direcionadores dos custos diretos e indiretos as horas por departamento. Tem como características de pesquisa análises quantitativas, descritiva e de coleta de dados com base em estudos de caso, que teve como base informações sobre os custos e as receitas auferidas no mês específico. A aplicação do método de custeio ABC possibilitou identificar e apontar as atividades relevantes do departamento fiscal, contábil, pessoal e financeiro. Identificar também os direcionadores de custos e suas respectivas bases de rateio para os recursos atribuídos às atividades de cada departamento e os direcionadores dos custos indiretos dessas atividades com a finalidade de atribuir aos clientes. Desta forma é possível identificar com segurança os custos de cada departamento e, posteriormente, o custo de cada cliente comparando, e com as apurações de resultados do exercício tornou-se possível analisar verticalmente o custo sobre a receita e o lucro sobre a receita. Verificou-se também quais clientes representam mais lucros e menos custos para a empresa. A aplicação do método de custeio ABC na empresa em estudo possibilitou melhor alocação dos custos indiretos e identificou quais departamentos consomem mais recursos sobre os serviços prestados aos clientes.
\end{abstract}

Palavras-chave: Métodos de custeio. Custeio ABC. Tomada de Decisão. Custos. Apuração de resultados. Direcionadores de Custos. Departamentos.

\footnotetext{
${ }^{1}$ Discente do oitavo semestre do curso de Ciências Contábeis da Faculdade La Salle de Lucas do Rio Verde-MT, matriculado na disciplina de Trabalho de Conclusão II. E-mail: leonardo thiago10@hotmail.com.

${ }_{2}^{2}$ Professor Docente do Curso de Ciências Contábeis da Faculdade La Salle e orientador do artigo. Email: leandro.franz@faculdadelasalle.edu.br.
} 


\section{INTRODUÇÃO}

Segundo Horngren (2004) a correta mensuração dos custos serve de base aos administradores tomarem as decisões cabíveis por meio dos relatórios contábeis que contabilizam corretamente seus custos.

E para que a empresa apresente este diferencial ao mercado, Horngren (2004) faz uma relação entre a contabilidade de custos e a contabilidade gerencial, dizendo que um método de custeio bem planejado irá influenciar diretamente ao contador gerencial poder apresentar os melhores produtos ou serviços aos seus clientes, com menores custos à empresa.

Ao longo dos anos a representatividade dos custos indiretos foi apresentada com maiores importâncias que o custo da mão-de-obra direta, visto que os custos indiretos são apropriados por meio de rateio - em bases de volume de produção como peso, horas-máquinas, horas-homem (SOUZA E DIEHL, 2009, p.145).

Ao analisar essa mudança, Souza e Diehl (2009) demonstram que a necessidade de um novo método de custeio era importante para a maior competitividade das empresas, que já estavam perdendo o controle sobre a mensuração correta do custo indireto pelo fato do mercado apresentar maior exigência quanto aos processos produtivos. Um dos motivos apresentados como mudança do mercado é o aumento do mix de produtos, menores ciclos de vida de produtos, entre outros.

Berti (2010) afirma que uma empresa consome recursos, com o objetivo de recuperá-los e ainda obter lucros no final e esse resultado poderá ser consumado se a empresa estiver preparada para implantar um processo de custeio sem a arbitrariedade de alocação dos custos, principalmente os indiretos.

Visando atender todas as necessidades informacionais de uma empresa para a melhor tomada de decisão baseada nos métodos de custeio, foi desenvolvido o método de custeio baseado em atividades (Activity-based costing) ou $A B C$, método de apuração dos custos dos produtos, serviços ou outros objetos de custeio com a seguinte filosofia: os recursos da empresa são consumidas pelas atividades executadas, e os produtos, serviços e outros objetos de custeio são resultados dessas atividades que requerem esses recursos (BERTI, 2009). Assim, os custos 
indiretos são rateados primeiramente nas atividades e, posteriormente, nos produtos, serviços e outros objetos de custeio que demandaram as atividades.

O custeio $\mathrm{ABC}$ é dividido em etapas que definem todo o processo de apropriação dos custos gerados pela atividade, e cada custo indireto deve ser relacionado com as suas respectivas atividades geradora dos custos. Utilizam-se direcionadores para que este rateio de custos indiretos sejam melhor aplicado em suas formas de consumo dos recursos, e o custo total seja evidenciado de forma correta para a melhor tomada de decisões pela empresa.

Conforme Fontoura (2013) a primeira etapa de avaliação do custeio ABC é identificar as atividades que utilizam dos recursos para gerar um produto ou serviço, como por exemplo, no departamento de compras o colaborador irá realizar as atividades de comprar as matérias - primas ou produtos para revenda, relacionar-se com fornecedores e priorizar os melhores.

A segunda etapa tem o objetivo de atribuir os custos dos recursos as atividades e, posteriormente, aos objetos de custeio (Megliorini, 2012).

O setor de prestação de serviços também necessita de um bom método para analisar os seus custos e o ABC pode ser um auxílio para este setor. Afirmado por Berti (2010), que o método de custeio ABC não se aplica apenas em empresas industriais, incluindo também para qualquer tipo de empresa que utilize a contabilidade de custos para tomadas de decisão.

Ao tema abordado surge a seguinte problemática: Quais serão os custos e resultados identificados por departamentos após a aplicação método de custeio ABC no escritório contábil?

Neste contexto, tem-se como objetivo geral analisar os custos e receitas através do método $\mathrm{ABC}$ para o escritório em estudo, dividida por departamentos e demonstrar a que consome mais recursos para a empresa.

Os objetivos específicos de identificar as premissas do processo da implantação do método $A B C$ no escritório contábil de Lucas do Rio Verde; analisar quais os direcionadores de custos são gerados a partir do $A B C$ e as vantagens e desvantagens do método de custeio nos escritórios contábeis; identificar também quais os resultados apurados pelo método $A B C$ na empresa contábil.

A pesquisa realizada sobre este tema, com a problemática e objetivos citados acima, busca analisar quais as principais vantagens e desvantagens para 0 escritório de contabilidade presente na cidade de Lucas do Rio Verde sobre a 
aplicação do método de custeio $A B C$. Partindo da justificativa de que o $A B C$ é uma ferramenta de gestão de custos que pode apresentar resultados positivos para a empresa, atribuindo corretamente os custos indiretos a cada atividade consumidora de recursos para prestação do serviço.

\section{REFERENCIAL TEÓRICO}

\subsection{Contabilidade de Custos}

Após a revolução industrial e o aumento das concentrações de empresas industriais, a contabilidade viu-se necessária a aplicação de novos métodos de mensuração e registros dessas atividades. Pode-se explanar assim:

Com o advento das indústrias, tornou-se mais complexa a função do contador que, para levantamento do balanço e apuração do resultado, não dispunha agora tão facilmente dos dados para poder atribuir valor aos estoques; seu valor de "Compras" na empresa comercial estava agora substituído por uma série de valores pagos pelos fatores de produção utilizados. (MARTINS, 2010, p. 20).

À medida que a competição global fora intensificada, para Horngren (2004), as empresas observaram a mudança na forma de produção de seus concorrentes, com crescentes variedades de produtos e tinham diferentes formas de consumo dos seus recursos.

A contabilidade de custos gera informações para a contabilidade financeira e gerencial, sendo ferramenta preponderante às empresas nas tomadas de decisões tanto para âmbito interno, como para o externo das empresas (HORNGREN, 2004, p. 2). Presta informações com base nas Normas de Contabilidade quando mensura e avalia os custos (objetivo da Contabilidade financeira) e fornecimento de informações de custos sobre produtos, serviços projetos, atividades, processo produtivo voltado para os usuários internos da empresa (Contabilidade Gerencial). Pode - se explicar tal necessidade da contabilidade gerencial como segue:

Devido ao crescimento das empresas, com o consequente aumento da distância entre administrador e ativos e pessoas administradas, passou a Contabilidade de Custos a ser encarada como uma eficiente forma de auxílio no desempenho dessa nova missão, a gerencial. (MARTINS, 2010, p. 21). 
Conforme Berti (2006), os custos originam-se de capitais, bens e serviços que gerem insumos utilizados na consecução de determinados objetivos chegando ao produto. Para o total entendimento sobre a contabilidade de custos e as suas finalidades podemos afirmar que:

1) Auxiliar o usuário na tomada de decisão, ou seja, servir como subsídio para atender às necessidades das gerências na administração, principalmente em três grandes grupos:

2) Informações que servem para a determinação da rentabilidade e do desempenho das diversas atividades da entidade, (comprar, industrializar e vender);

3) Informações que auxiliam a gerência a planejar, a controlar e administrar o desenvolvimento das operações;

4) Informações para a tomada de decisões, principalmente em se tratando de: a) planejamento e controle das operações; b) nível mínimo de vendas desejado; c) custo e ganho marginal do produto;

d) eficiência da força de trabalho humano e dos materiais aplicados;

e) maximização de lucros mediante análise do mix de produtos. (BERTI, 2006, p. 25).

Os métodos de custeio surgiram para suprir a necessidade das empresas em calcular e apresentar corretamente os custos indiretos, de forma que possam reduzir estes custos e alocá-los de acordo com o consumo de seus recursos na prestação de serviços e venda de mercadorias. Escolher o melhor método de custeio, no caso deste trabalho, em empresas contábeis que prestam serviços aos usuários internos e externos, podem atender as necessidades específicas da empresa e conseguir mensurar os custos decorrentes de seu processo de prestação de serviços, e de acordo com cada tipo de atividade e o comportamento destes custos dentro dela. Abaixo serão apresentados os 3 principais métodos de custeio existentes.

\subsection{Métodos de custeio}

No ramo da contabilidade de custos existem 3 tipos de métodos para avaliar os custos incorridos pelas empresas, e no Brasil elas devem ser utilizadas para a necessidade em que a empresa se adequa, auxiliando assim, na melhor tomada de decisão em relação aos custos de produtos ou serviços.

O método de Custeio por Absorção para apuração dos custos é o mais utilizado no Brasil, por seguir todos os princípios fundamentais de contabilidades adotadas no país e por ter maior aceitação ao fisco brasileiro. E consiste em apurar 
os custos dos bens basicamente, atribuindo integralmente os custos diretos e indiretos, fixos e variáveis a cada unidade produzida que tiveram origem no processo de produção. Berti (2010), afirma que no método de custeio por absorção os custos diretos são alocados aos produtos com base nas quantidades de recursos consumidos efetivamente no processo.

O método de custeio por absorção é aceito pelo fisco, com base na legislação fiscal, cujo art. 302 do Decreto $n^{\circ}$ 9.580, De Novembro de 2018 prevê os custos de bens ou serviços, obrigatoriamente:

I - O custo de aquisição de matérias-primas e de outros bens ou serviços aplicados ou consumidos na produção, observado 0 disposto no art. 301;

II - O custo do pessoal aplicado na produção, inclusive de supervisão direta, na manutenção e na guarda das instalações de produção;

III - os custos de locação, manutenção e reparo e os encargos de depreciação dos bens aplicados na produção;

IV - Os encargos de amortização diretamente relacionados com a produção; V - os encargos de exaustão dos recursos naturais utilizados na produção. (BRASIL, Decreto $n^{\circ}$ 9.580, De novembro de 2018. Custos de produção).

Portanto, conforme Decreto $n^{\circ} 9.580$ (2018) a legislação fiscal atualizada do regulamento do imposto sobre a renda por meio deste decreto, descreve como integrante dos custos de produção os custos diretos e indiretos, fixos e variáveis. Concluindo que o método de custeio por absorção apresenta uma maior importância para as indústrias brasileiras, e são aceitos para apuração do lucro real e da base de cálculo para a contribuição social sobre o lucro por ser um sistema que atende aos princípios contábeis (FONTOURA, 2013, p 83).

O custeio variável, método citado como mais utilizado nesta seção, conforme Megliorini (2012) é o método de custeio que tem como objetivo a atribuição dos custos que são considerados variáveis aos seus produtos, sem levar em consideração os custos fixos pelo fato destes custos utilizar-se de critério de rateio causador de arbitrariedade. O custeio variável apresenta estrutura visando atender à administração da empresa, e inclui ações como:

a) Identificar os produtos que mais contribuem para a lucratividade da empresa;

b) Determinar os produtos que podem ter suas vendas incentivadas ou reduzidas e aqueles que podem ser excluídos da linha de produção; 
c) Identificar os produtos que proporcionam maior rentabilidade quando existem fatores que limitam a produção (gargalos), permitindo o uso mais racional desses fatores;

d) Definir o preço dos produtos em condições especiais, por exemplo, para ocupar eventual capacidade ociosa;

e) Decidir entre comprar e fabricar;

f) Determinar o nível mínimo de atividades para que o negócio passe a ser rentável;

g) Definir, em uma negociação com o cliente, o limite de desconto permitido; (MEGLIORINI, 2012, p. 137).

Todas estas ações podem auxiliar diretamente aos gestores da empresa no processo decisório, em relação a margem de contribuição do produto após a dedução dos custos e despesas variáveis (MEGLIORINI, 2012).

\subsection{Custeio Baseado em Atividades (ABC)}

O método de custeio ABC, como trata Fontoura (2013) surgiu para suprir as mudanças que ocorreram ao longo do tempo nas empresas em relação a tomada de decisões. O método $A B C$ têm em sua essência um auxílio maior aos gestores da empresa para decidir corretamente quais seriam os seus resultados, ao analisar que - $A B C$ estaria seguindo o avanço das organizações para uma ferramenta mais estratégica, e que os métodos de custeio básicos já não eram ferramentas para o ramo gerencial, com intuito de aprimorar a alocação dos custos e despesas indiretos fixos aos produtos.

O método de custeio $A B C$ tem como objetivo principal avaliar com precisão as atividades internas que uma empresa pode gerar seus produtos e serviços, utilizando como base seus direcionadores de custos para alocar as despesas e os custos indiretos a eles (MARTINS, 2010). Por isso este método é chamado de Custeio baseado em atividades (ABC). Segundo Beulke (2006) o método ABC possui características de apropriação de todos os custos e despesas diretas possíveis aos produtos, serviços e às mercadorias, sejam os custos fixos ou variáveis.

O ABC apresenta como diferença principal dos outros métodos de custeio (neles, os custos são classificados por setores ou centro de custos), a forma como são classificados os custos para a apuração. A aferição inicial ocorre por meio das atividades, ou seja, atividades consomem recursos e produtos consomem 
atividades, dando maior importância a correta alocação dos custos indiretos gerados. Conforme Berti (2009, p.75):

\begin{abstract}
Assim, se os custos medem o consumo de recursos das empresas para a realização de suas atividades, o custeio correto, como é evidente, deverá (1) verificar como os recursos são efetivamente consumidos pelas diferentes atividades da empresa e, depois, (2) verificar como os produtos ou serviços da empresa - aqueles que ela venda no mercado para recuperar os seus custos e realizar o objetivo do lucro - consomem ou precisam de tais atividades onerosas (que consomem recursos).
\end{abstract}

Concluindo assim conforme Blocher et al (2007, p. 132), explicam que o método de custeio $A B C$ apresenta a mais correta apuração dos custos, e que cada atividade que consome os recursos até chegar ao produto final, possui alocação eficaz desses custos com foco nos indiretos e, com isso, as informações prestadas ao usuário sobre o valor a ser agregado ao produto ou serviço, acarretará em um lucro correto a ser captado à empresa. É uma ferramenta poderosa de gestão de custos a qualquer tipo de empresa, pois a análise se desenvolve a partir das atividades que vão receber os custos indiretos gerados.

A base de interesse do ABC será concentrada nos gastos indiretos em que a prestação de serviço ou produção irá gerar em relação ao consumo de recursos efetuados por cada atividade. Não necessariamente todas as atividades efetuadas pela empresa, mas sim, as atividades relevantes que vão gerar custos para o produto. Assim exemplificado no esquema abaixo:

O Custo $\mathrm{ABC}$ é definido comumente como um método de custeamento que atribui primeiro os custos para as atividades, e depois aos produtos, baseado no uso de atividades de cada produto. O custeamento baseado em atividades e fundamentado no conceito: produtos consomem atividades, atividades consomem recursos. (PADOVEZE, 2010, p. 366).

Este esquema evidencia que o método de custeio $A B C$ é a ferramenta que pode impactar diretamente ao preço do produto consumido pelo mercado, e a empresa poderá obter melhores resultados nos seus demonstrativos contábeis. Por meio de aplicação do método de custeio ABC é possível saber o Por quê os custos ocorrem, e com base na resolução dessa pergunta, as empresas podem melhorar sua eficiência operacional (SOUZA \& DIEHL, 2009, p. 147). 
Segundo Padoveze (2010, p. 365) "método de custeamento baseado em atividades $(A B C)$, que procura aprimorar o custeamento de produtos, através de mensurações corretas dos custos fixos indiretos, em cimas das atividades geradoras desses custos".

\subsubsection{Direcionadores de Custos Baseado em Atividades}

Os direcionadores de custos são a base para a aplicação correta do método $A B C$, para que os custos indiretos sejam alocados a cada atividade que consome recursos. O custeio baseado em atividades rejeita a implementação tradicional de que os custos indiretos sejam alocados diretamente ao produto, e neste caso, é preciso considerar que:

O custeio baseado em atividades rejeita aquela suposição e, em vez disso, desenvolve a ideia de direcionadores de custo que vincula, diretamente, as atividades executadas aos produtos fabricados. Esses direcionadores de custos medem o consumo médio ocorrido, em cada atividade, pelos vários produtos. (ATKINSON, et al., 2011, p. 308).

Neste sentido, a utilização do método $A B C$ é fundamental para que saiba quais são os direcionadores de custos de cada atividade exercida pela empresa, para que não distribua indevidamente os gastos incorridos dessas atividades por meio de rateio, fator que influencia na perda da essência de ferramenta gerencial como auxílio na tomada de decisões.

Segundo Martins (2003), para que sejam alocados corretamente os custos aos produtos ou serviços prestados, deve ser feita com muito critério e de acordo com as prioridades encontradas. Como os custos diretos são identificados de forma clara, direta e objetiva, utiliza-se a alocação direta.

Os custos indiretos, foco do método de custeio ABC, para Martins (2003), pode ser alocado às atividades por meio de rastreamento ou rateio. $O$ rastreamento é o critério mais confiável por fazer a alocação correta dos custos da atividade sem arbitrariedade, ao contrário do rateio, que serão utilizados caso não possa ser aplicado a alocação direta ou o rastreamento (MARTINS, 2003).

\section{METODOLOGIA}


A pesquisa é de cunho descritivo com abordagem quantitativa, seguindo 0 padrão de pesquisa bibliográfica e os procedimentos de coleta de dados através da técnica de estudo de caso, desenvolvida com base em material já elaborado, constituído principalmente de livros, e arquivos eletrônicos constantes de leis. Segundo Gil (2007, p.66) "a única diferença entre ambas está na natureza das fontes. Enquanto a pesquisa bibliográfica se utiliza fundamentações das contribuições dos diversos autores, a pesquisa documental vale-se de materiais que não receberam ainda um tratamento analítico". Conforme Gil (2002, p. 54), o estudo de caso pode ser explicado da seguinte forma: "Consiste no estudo profundo e exaustivo de um ou poucos objetos, de maneira que permita seu amplo e detalhado conhecimento".

A pesquisa para o devido artigo terá como objeto de estudo e análise de livros, legislações vigentes, como: O Decreto $n^{\circ}$ 9.580, De 22 De Novembro De 2018, Livros de Contabilidade Gerencial e de Custos, documentos estes para base referencial teórica. Para análise será utilizado o escritório contábil de Lucas do Rio Verde composta por gestores com registro no Conselho Regional de Contabilidade, de reconhecida capacidade técnica e com experiência na área contábil de longa data. Devidamente credenciada junto aos órgãos competentes, habilitada para a prestação de serviços contábeis em geral, que possui um quadro de 92 clientes e com maior predominância de empresas com tributação no regime do Simples Nacional, analisado especificamente os seus métodos de custeio e ao levantamento de dados por meio do método de custeio $A B C$.

A execução da fase aplicada partirá através do levantamento de dados feitos através do método $A B C$, análise de documentos das demonstrações contábeis e levantamentos dos dados, sendo utilizada uma entrevista informal juntamente aos gestores do escritório e colaboradores de cada departamento, e sendo identificada as atividades exercidas na empresa contábil em questão, os tipos de tributação de cada empresa cliente do escritório, e o correto direcionamento dos custos encontrados que são consumidos por cada atividade para a prestação do serviço aos clientes de Lucas do Rio Verde.

Foram coletados, através de relatórios disponibilizados pelo escritório contábil objeto de estudo, os custos referentes à Mão de obra dos funcionários (Salários + Encargos) que são responsáveis na prestação do serviço contábil para os seus 
clientes, bem como os custos indiretos ligados a execução do serviço mensalmente, os departamentos em que a organização é dividida, os regimes tributários de cada empresa cliente, a quantidade de empresas presentes no quadro de cliente, e o tempo mínimo para cada atividade para a prestação dos serviços.

Os dados base deste estudo foram coletados internamente no escritório contábil, iniciando o processo na busca de informações sobre todos os custos incorridos no mês para cálculo exato e buscando atender aos objetivos da pesquisa.

A partir deste pensamento, os dados foram levantados por departamentos subdivididos internamente e que consomem os recursos para a prestação do serviço ao cliente. Cada departamento possui o seu valor de mão de obra, e são compostos pelo departamento fiscal, departamento contábil, departamento pessoal e departamento financeiro. Suas tarefas são diferentes no cotidiano e para que sejam mensurados os custos, foram mapeadas as atividades relevantes de cada departamento para a realização do cálculo.

Complementa Souza e Diehl (2009), que os custos se originam após a execução das atividades, gerando consumo de recursos. E esta execução de atividade não pode ser tratada somente com a proporcionalidade do volume do serviço prestado, por se tratar de clientes distintos e que necessitam maiores exigências que outros menos exigentes. $E$ para a aplicação do $A B C$ na organização contábil, os direcionadores de custos de melhor encaixe nos cálculos e utilizados como base é o tempo empregado por regimes tributários em que os clientes estão enquadrados.

Ao identificar os departamentos, analisar quais atividades relevantes de cada um e encontrar a base de rateio que obtivesse relação com os objetos de custos, o método de custeio $A B C$ foi aplicado para a mensuração dos custos totais que serão confrontados com as receitas do escritório contábil.

Ao finalizar todo o processo de aplicação do método $A B C$, os resultados auferidos podem auxiliar ao gestor da empresa na melhor tomada de decisão junto a análise dos custos incorridos nas atividades mapeadas, podendo apresentar melhorias aos departamentos que apresentar o menor resultado.

\section{ANÁLISE E DISCUSSÃO DOS RESULTADOS}


Neste capítulo serão apresentados os resultados encontrados a partir das análises e coleta dos dados internos da empresa contábil objeto da pesquisa. Inicialmente serão informados os dados coletados na empresa e, posteriormente, apresentados os cálculos realizados por meio do método $A B C$ e na sequência o resultado do escritório contábil, por fim são apresentadas sugestões quanto ao custeio de cada departamento.

\subsection{Empresa Pesquisada}

O escritório contábil base do estudo desta pesquisa constituída em 2008, composta por gestores com registro no Conselho Regional de Contabilidade, de reconhecida capacidade técnica e com experiência na área contábil de longa data. Devidamente credenciada junto aos órgãos competentes, habilitada para a prestação de serviços contábeis em geral. Possui um quadro de clientes no total de 92, sendo enquadradas em diferentes regimes tributários existentes na legislação brasileira e com a missão de proporcionar a eles informações com confiabilidade, fidedignidade, dentro da competência e que contribua com a otimização da gestão empresarial e melhores tomadas de decisões.

$\mathrm{Na}$ empresa em estudo há uma diferenciação de departamentos que prestam serviço a um cliente, sendo eles, departamento fiscal, departamento contábil, departamento pessoal $(\mathrm{RH})$ e departamento financeiro. No departamento fiscal, suas atribuições mensais por cliente são efetuadas por 6 funcionários, no departamento contábil somente 1 funcionário executa as atividades, o departamento pessoal comporta também 1 funcionários e o departamento financeiro é composto pelo gestor da empresa.

Quadro 1-Quantidade de funcionários por departamento

\begin{tabular}{|c|c|}
\hline DEPARTAMENTOS & $\begin{array}{l}\text { QUANTIDADE DE } \\
\text { COLABORADORES }\end{array}$ \\
\hline DEPARTAMENTO FISCAL & 6 \\
\hline DEPARTAMENTO CONTÁBL & 1 \\
\hline DEPARTAMENTO PESSOAL & 1 \\
\hline DEPARTAMENTO FINANCEIRO & 1 \\
\hline TOTAL & 9 \\
\hline
\end{tabular}

Fonte: Dados da pesquisa, 2019.

\subsection{Aplicação do Custeio $A B C$ ao escritório contábil em estudo}


Com o propósito de aplicação do método de custeio $A B C$ na empresa em estudo, foram realizados levantamentos sobre as atividades relevantes para identificar os direcionadores de custos, calcular as bases de rateio, atribuir os custos diretos utilizando o rateio para cada atividade nos departamentos, realizar a alocação dos custos indiretos às atividades relevantes de cada departamento e, por fim, realizar a apuração dos resultados da empresa evidenciando qual departamento obteve os maiores resultados. Os departamentos do escritório contábil apresentam um quadro com a quantidade de funcionários para cada setor de prestação dos serviços.

\subsubsection{Identificação das atividades relevantes}

Após a coleta das informações e a divisão dos centros de custos principais por departamentos, por meio de entrevistas informais com os funcionários de cada departamento, foram obtidos os seguintes dados:

Quadro 2 - Atividades relevantes por departamento

\begin{tabular}{|c|c|c|c|}
\hline $\begin{array}{l}\text { DEPARTAMENTO } \\
\text { FISCAL }\end{array}$ & $\begin{array}{l}\text { DEPARTAMENTO } \\
\text { CONTÁBIL }\end{array}$ & $\begin{array}{l}\text { DEPARTAMENTO } \\
\text { PESSOAL }\end{array}$ & $\begin{array}{l}\text { DEPARTAMENTO } \\
\text { FINANCEIRO }\end{array}$ \\
\hline $\begin{array}{l}\text { LANÇAMENTO DE } \\
\text { ENTRADAS E } \\
\text { SAÍDAS }\end{array}$ & $\begin{array}{c}\text { BAIXA DE NOTAS } \\
\text { FISCAIS E } \\
\text { LANÇAMENTOS } \\
\text { CONTÁBEIS }\end{array}$ & $\begin{array}{l}\text { CÁLCULO FOLHA DE } \\
\text { PAGAMENTO }\end{array}$ & $\begin{array}{l}\text { CONTAS A } \\
\text { PAGAR }\end{array}$ \\
\hline $\begin{array}{l}\text { APURAÇÃO DE } \\
\text { IMPOSTOS }\end{array}$ & $\begin{array}{l}\text { CONCILIAÇÕES } \\
\text { CONTÁBEIS E } \\
\text { FISCAIS }\end{array}$ & ADMISSÕES/RECISÕES/FÉRIAS & $\begin{array}{l}\text { CONTAS A } \\
\text { RECEBER }\end{array}$ \\
\hline \multirow[t]{3}{*}{$\begin{array}{l}\text { TRANSMISSÃO DE } \\
\text { EFD - FISCAL E } \\
\text { CONTRIBUIÇÕES }\end{array}$} & $\begin{array}{c}\text { APURAÇÃO E } \\
\text { TRANSMISSÃO DE } \\
\text { SPED ECF, ECD }\end{array}$ & RAIS/CAGED/DIRF/IR & $\begin{array}{l}\text { CONTROLES } \\
\text { BANCÁRIOS }\end{array}$ \\
\hline & & AFASTAMENTOS INSS & $\begin{array}{l}\text { COBRANÇA A } \\
\text { CLIENTES }\end{array}$ \\
\hline & & $\begin{array}{c}\text { SEFIP/GUIAS/RECÁLCULOS } \\
\text { (INSS, FGTS, IR) }\end{array}$ & \\
\hline
\end{tabular}

Fonte: Dados da pesquisa, 2019.

Os departamentos representam os centros de custos do escritório contábil e as atividades de cada departamento serão custeadas de acordo com o seu consumo de recursos, após encontrar quais os direcionadores de custos serão utilizados para aplicação do método $A B C$, sendo estas atividades consumidoras dos recursos coletados na empresa contábil. 


\subsubsection{Direcionadores dos Custos das Atividades}

Neste primeiro estágio, é preciso definir como as atividades consomem os recursos que são investidos pela empresa para a consecução do trabalho, e estes recursos deverão ser alocados a cada atividade de acordo com o que realmente será consumido por aquela atividade dos departamentos encontrados. Como os custos diretos são gastos facilmente atribuídos aos clientes, elas serão alocadas a cada departamento utilizando o total de horas coletadas por cliente.

Os custos indiretos levantados por meio da coleta dos dados internos no escritório contábil em estudo, serão valores para custear as atividades. E para que o método $\mathrm{ABC}$ seja aplicado corretamente, o direcionador de custo identificado para o consumo de recursos pelas atividades serão o tempo empregado total de cada cliente. O cálculo utilizado para apurar as horas mensais foram o seguinte: número de colaboradores por setor multiplicado pelas horas diárias de trabalho e multiplicado pelo total de dias úteis para a consecução dos serviços prestados por cliente. A tabela abaixo demonstra os cálculos realizados que foi citado acima.

Tabela 1 - Horas mensais dos departamentos

\begin{tabular}{c|c|c|c|c|c|c|c}
\hline Departamentos & $\begin{array}{c}\text { Simples } \\
\text { Nacional }\end{array}$ & $\%$ & $\begin{array}{c}\text { Lucro } \\
\text { Presumido }\end{array}$ & $\%$ & Lucro Real & $\%$ & Total \\
\hline Fiscal & 528 horas & $50 \%$ & 396 horas & $38 \%$ & 132 horas & $12 \%$ & 1056 horas \\
\hline Contábil & 88 horas & $50 \%$ & 66 horas & $38 \%$ & 22 horas & $12 \%$ & 176 horas \\
\hline Pessoal & 88 horas & $50 \%$ & 66 horas & $38 \%$ & 22 horas & $12 \%$ & 176 horas \\
\hline Financeiro & 88 horas & $50 \%$ & 66 horas & $38 \%$ & 22 horas & $12 \%$ & 176 horas \\
\hline
\end{tabular}

Fonte: Dados da pesquisa, 2019.

A Tabela 1 serve de base para a alocação dos custos indiretos às atividades para que os recursos sejam consumidos de acordo com seu percentual de execução dos serviços, pelas horas totais por cliente. Para chegar ao total de 528 horas do departamento fiscal para o cliente do Simples Nacional, utilizou-se a multiplicação das 4 horas diárias dos serviços executados por estes clientes, por 6 colaboradores do departamento e pelos 22 dias úteis para execução do trabalho, com total de 528 horas representando $50 \%$ das horas totais do departamento.

As horas totais para o cliente do Lucro Presumido, utilizaram-se dos mesmos cálculos informados anteriormente, multiplicação do total de colaboradores, 22 dias 
úteis de trabalho e total de horas diárias, que levantados no escritório contábil, por 3 horas ao dia para estes clientes, que totalizaram 396 horas mensais representando $38 \%$ das horas totais.

Para as empresas de Lucro Real, foram calculados pela multiplicação do número de colaboradores do departamento fiscal multiplicando assim por 22 dias úteis ao mês de trabalho e 1 horas diária para consecução do serviço, totalizando 132 horas mensais com representatividade de $12 \%$ das horas totais.

O departamento contábil é composto por 1 colaborador para desempenhar as atividades que consomem os recursos, e os cálculos realizados da mesma forma que citado anteriormente para o departamento fiscal, e totalizando para o cliente do Simples Nacional o total de 88 horas ou $50 \%$ do tempo total para o departamento, para os clientes do Lucro Presumido com 66 horas ou 38\% e para os clientes do Lucro Presumido 22 horas ou $12 \%$ do tempo total para o departamento contábil.

O departamento pessoal é composto por 1 colaborador e através de reuniões a este responsável, foram auferidas o tempo de execução do trabalho total em relação aos 22 dias úteis do mês. $O$ total de horas coletadas para o departamento pessoal foi de 176 horas mensais, divididas entre as empresas optantes pelo Simples Nacional como 88 horas, empresas do Lucro Real em 22 horas/mês e empresas do Lucro Presumido 66 horas/mês para realizar cada atividade por meio deste departamento.

O departamento financeiro composto por 1 colaborador e utiliza de 4 horas diárias para as empresas do Simples Nacional, 3 horas para as empresas do Lucro Presumido e 1 horas para as empresas do Lucro real. Multiplica-se por número de colaborador, neste caso por 1, e por 22 dias úteis de trabalho possível para o mês, totalizando assim as horas totais de execução do serviço para cada cliente. Para o Simples Nacional o total encontrado após o cálculo é de 88 horas ou $50 \%$ do tempo total, para o Lucro Presumido 66 horas mensais ou $38 \%$ e para os clientes do Lucro Real 22 horas mensais ou $12 \%$ do tempo total para o departamento financeiro de 176 horas mensais.

Os percentuais foram arredondados, após cálculos pela ferramenta excel, sendo assim as divergências de somatória não altera quaisquer resultados aqui apresentados.

\subsubsection{Atribuição dos custos aos departamentos}


A princípio foram apurados, com base em documentos emitidos pelo sistema de informações da empresa sobre o valor total de Mão de Obra direta juntamente com os encargos decorrentes da folha de pagamento que o quadro de funcionários está consumindo. Foram coletados os valores mensais referente ao consumo total de recursos diretos por departamento e dividido pelas horas totais calculadas anteriormente pela Tabela 1.

O critério utilizado para os custos diretos será utilizado por meio de alocação direta aos serviços prestados e abaixo a Tabela 2 evidencia os valores unitários para multiplicar pelo total de horas por cliente para atribuição dos custos diretos de acordo com o consumo de recursos para cada cliente.

Tabela 2 - Custos diretos por departamento

\begin{tabular}{|c|c|c|c|c|c|}
\hline $\begin{array}{l}\text { CUSTOS DIRETOS/ } \\
\text { DEPARTAMENTO }\end{array}$ & FISCAL & CONTÁBIL & PESSOAL & FINANCEIRO & TOTAL \\
\hline Salários + Encargos & $\mathrm{R} \$ 10.464,93$ & $\mathrm{R} \$ 2.464,02$ & $\mathrm{R} \$ 2.313,63$ & $R \$ 1.500,00$ & $\mathrm{R} \$ 16.742,58$ \\
\hline Total em horas & 1056 & 176 & 176 & 176 & 1584 \\
\hline $\begin{array}{c}\text { Valor unitário por } \\
\text { hora }\end{array}$ & 9,91 & $R \$ \quad 14,00$ & $R \$ \quad 13,15$ & 8,52 & 45,58 \\
\hline (\%) MOD & $63 \%$ & $15 \%$ & $14 \%$ & $9 \%$ & $100 \%$ \\
\hline
\end{tabular}

Fonte: Dados da pesquisa, 2019.

$\mathrm{Na}$ Tabela 2 podem-se observar quais são os departamentos com maiores custos dentro da organização contábil, e por meio de aplicação do método $A B C$ a alocação destes custos diretos são mais detalhados e podem ser alocadas ao resultado com critérios mais adequados e preciso do que por outros métodos de custeio.

Observa-se também a representatividade dos custos diretos por departamento e apresenta qual é o setor que mais consome recursos da organização, e por meio da Tabela 2 é evidente que o departamento fiscal é o setor de maior custo direto com $63 \%$ do total de recursos gastos com os departamentos referente ao total de mão de obra aos colaboradores.

Tabela 3 - Custos indiretos mensais do escritório contábil

\begin{tabular}{|l|l|}
\hline \multicolumn{2}{|c|}{ CUSTOS INDIRETOS } \\
\hline ALUGUEL & $\mathrm{R} \$ 2.050,00$ \\
\hline ENERGIA ELÉTRICA & $\mathrm{R} \$ 1.300,00$ \\
\hline TELEFONE & $\mathrm{R} \$ 250,00$ \\
\hline SOFTWARES & $\mathrm{R} \$ 2.899,75$ \\
\hline
\end{tabular}




\begin{tabular}{|c|c|}
\hline INTERNET & $\mathrm{R} \$ 199,00$ \\
\hline DEPRECIAÇÃO COMPUTADORES & $\mathrm{R} \$ 187,50$ \\
\hline IMPOSTOS (SIMPLES NACIONAL) & $\mathrm{R} \$ 510,00$ \\
\hline ISSQN & $R \$ 295,00$ \\
\hline TOTAL & $\mathbf{R} \$ 7.691,25$ \\
\hline
\end{tabular}

Fonte: Dados da pesquisa, 2019.

Os custos indiretos identificados na prestação dos serviços contábeis mensal do escritório serão demonstrados na Tabela 3 e, posteriormente, serão atribuídos aos departamentos com seus respectivos valores. Este cálculo é baseado no método $A B C$, onde os custos indiretos serão alocados sem distorções e sua mensuração será baseada no percentual de representatividade de mão de obra correspondente aos departamentos.

Nesta fase, a Tabela 4 representam os cálculos realizados para alocação dos custos indiretos mensais do escritório contábil aos seus respectivos departamentos, com objetivo de evidenciação do setor que consome mais estes recursos.

Tabela 4 - Custos indiretos por departamento

\begin{tabular}{|c|c|c|c|c|c|c|c|c|c|c|}
\hline \multirow{2}{*}{$\begin{array}{l}\text { CUSTOS INDIRETOS } \\
\text { \% DE REPRESENTATIVIDADE } \\
\text { DO SETOR }\end{array}$} & \multicolumn{2}{|c|}{$\begin{array}{c}\text { MÉDIA MENSAL - } \\
2019 \\
\end{array}$} & \multicolumn{2}{|c|}{$\begin{array}{c}\text { DEPARTAMENTO } \\
\text { FISCAL } \\
\end{array}$} & \multicolumn{2}{|c|}{$\begin{array}{c}\text { DEPARTAMENTO } \\
\text { CONTÁBIL }\end{array}$} & \multicolumn{2}{|c|}{$\begin{array}{c}\text { DEPARTAMENT } \\
\text { O PESSOAL }\end{array}$} & \multicolumn{2}{|c|}{$\begin{array}{l}\text { DEPARTAMENTO } \\
\text { FINANCEIRO }\end{array}$} \\
\hline & & & & $3 \%$ & & $5 \%$ & & $14 \%$ & & \\
\hline Aluguel & $\mathrm{R} \$$ & $2.050,00$ & $\mathrm{R} \$$ & $1.281,35$ & $\mathrm{R} \$$ & 301,70 & $\mathrm{R} \$$ & 283,29 & $\mathrm{R} \$$ & 183,66 \\
\hline Energia & $\mathrm{R} \$$ & $1.300,00$ & $\mathrm{R} \$$ & 812,56 & $\mathrm{R} \$$ & 191,32 & $\mathrm{R} \$$ & 179,64 & $\mathrm{R} \$$ & 116,47 \\
\hline Telefone & $\mathrm{R} \$$ & 250,00 & $\mathrm{R} \$$ & 156,26 & $\mathrm{R} \$$ & 36,79 & $\mathrm{R} \$$ & 34,55 & $\mathrm{R} \$$ & 22,40 \\
\hline Seguros & $\mathrm{R} \$$ & - & $\mathrm{R} \$$ & - & $\mathrm{R} \$$ & - & $\mathrm{R} \$$ & - & $\mathrm{R} \$$ & - \\
\hline Softwares & $\mathrm{R} \$$ & $2.899,75$ & $\mathrm{R} \$$ & $1.812,49$ & $\mathrm{R} \$$ & 426,76 & $\mathrm{R} \$$ & 400,71 & $\mathrm{R} \$$ & 259,79 \\
\hline Internet & $\mathrm{R} \$$ & 199,00 & $\mathrm{R} \$$ & 124,38 & $\mathrm{R} \$$ & 29,29 & $\mathrm{R} \$$ & 27,50 & $\mathrm{R} \$$ & 17,83 \\
\hline Depreciação - Computadores & $\mathrm{R} \$$ & 187,50 & $\mathrm{R} \$$ & 117,20 & $\mathrm{R} \$$ & 27,59 & $\mathrm{R} \$$ & 25,91 & $\mathrm{R} \$$ & 16,80 \\
\hline Impostos (Simples Nacional) & $\mathrm{R} \$$ & 510,00 & $\mathrm{R} \$$ & 318,77 & $\mathrm{R} \$$ & 75,06 & $\mathrm{R} \$$ & 70,48 & $\mathrm{R} \$$ & 45,69 \\
\hline ISSQN & $\mathrm{R} \$$ & 295,00 & $\mathrm{R} \$$ & 184,39 & $\mathrm{R} \$$ & 43,42 & $\mathrm{R} \$$ & 40,77 & $\mathrm{R} \$$ & 26,43 \\
\hline TOTAL & $\mathbf{R} \$$ & $7.691,25$ & $\mathbf{R} \$$ & $4.807,41$ & $\mathbf{R} \$$ & $1.131,93$ & $\mathbf{R} \$$ & $1.062,84$ & $\mathbf{R} \$$ & 689,07 \\
\hline
\end{tabular}

Fonte: Dados da pesquisa, 2019.

Analisando a Tabela 4, podemos afirmar que a distribuição dos custos indiretos por departamento baseou Tabela 2 de acordo com o percentual de representatividade da mão de obra de cada departamento, a partir desse ponto, observa-se que o departamento fiscal com maior consumo dos custos indiretos em suas atividades pois é o setor com maior disponibilidade de colaboradores prestando os serviços mensais. Totalizando $\mathrm{R} \$ 4.807,41$ para o departamento fiscal, $\mathrm{R} \$$ 1.131,93 para o departamento contábil, $\mathrm{R} \$ 1.062,84$ para o departamento pessoal e $\mathrm{R} \$ 689,07$ para o departamento financeiro. 


\subsubsection{Alocação dos Custos diretos aos departamentos}

Com base nos estudos e metodologia, foram definidos como critério para os custos referente a mão de obra, a alocação direta aos clientes.

Tabela 5 - Custos diretos atribuídos aos clientes

\begin{tabular}{|l|c|c|c|c|}
\hline DEPARTAMENTO & $\begin{array}{c}\text { SIMPLES } \\
\text { NACIONAL }\end{array}$ & $\begin{array}{c}\text { LUCRO } \\
\text { PRESUMIDO }\end{array}$ & LUCRO REAL & $\begin{array}{c}\text { CUSTOS } \\
\text { DIRETOS } \\
\text { TOTAIS }\end{array}$ \\
\hline FISCAL & $\mathrm{R} \$ 5.232,47$ & $\mathrm{R} \$ 3.924,35$ & $\mathrm{R} \$ 1.308,12$ & $\mathrm{R} \$ 10.464,93$ \\
\hline CONTÁBIL & $\mathrm{R} \$ 1.232,01$ & $\mathrm{R} \$ 924,01$ & $\mathrm{R} \$ 308,00$ & $\mathrm{R} \$ 2.464,02$ \\
\hline PESSOAL & $\mathrm{R} \$ 1.156,82$ & $\mathrm{R} \$ 867,61$ & $\mathrm{R} \$ 289,20$ & $\mathrm{R} \$ 2.313,63$ \\
\hline FINANCEIRO & $\mathrm{R} \$ 750,00$ & $\mathrm{R} \$ 562,50$ & $\mathrm{R} \$ 187,50$ & $\mathrm{R} \$ 1.500,00$ \\
\hline TOTAL & $\mathbf{R} \$ \mathbf{8 . 3 7 1 , 2 9}$ & $\mathbf{R} \$ \mathbf{6 . 2 7 8 , 4 7}$ & $\mathbf{R} \$ \mathbf{2 . 0 9 2 , 8 2}$ & $\mathbf{R} \$ \mathbf{1 6 . 7 4 2 , 5 8}$ \\
\hline
\end{tabular}

Fonte: Dados da pesquisa, 2019.

Conforme a Tabela 5, os valores alocados a cada cliente foram definidos pelos cálculos aplicando os percentuais das horas apuradas na Tabela 1 de forma a custear cada cliente com seus devidos gastos com mão de obra dos departamentos apresentados. Como destaque, para os clientes do Simples Nacional os custos diretos foram de $R \$ 8.371,29$, para o Lucro Presumido o total de $R \$ 6.278,47$ e para o Lucro Real o total de $R \$ 2.092,82$ e o total de custos em $R \$ 16.742,58$ por meio da alocação direta e posteriormente serão somados aos custos indiretos atribuídos às atividades.

\subsubsection{Rateio dos custos indiretos por atividades}

Os custos indiretos que já foram separados anteriormente por departamentos e as alocações destes com base nos percentuais de representatividade dos custos diretos, agora serão rateados às atividades em se relacionam por meio de rastreamento, utilizando o tempo trabalhado como principal direcionador para cada atividade.

A Tabela 6 apresenta as bases de rateio por meio de média percentual calculada sobre as horas totais do departamento fiscal, para que os custos indiretos sejam alocados a cada atividade de forma justa.

Tabela 6 - Média percentual do tempo utilizado no departamento fiscal por atividades

\begin{tabular}{c|c}
\hline \multicolumn{1}{c|}{ ATIVIDADES } & \% TOTAL DO TEMPO \\
\hline EFETUAR LANÇAMENTO DE ENTRADAS E SAÍDAS & $98 \%$
\end{tabular}


\begin{tabular}{l|c} 
APURAÇÃO DE IMPOSTOS & $1 \%$ \\
$\begin{array}{l}\text { TRANSMISSÃO DE EFD - FISCAL E CONTRIBUIÇÕES/LIVROS } \\
\text { FISCAIS }\end{array}$ & $1 \%$ \\
\hline \multicolumn{1}{c|}{ TOTAL } & $\mathbf{1 0 0 \%}$
\end{tabular} Fonte: Dados da pesquisa, 2019.

Essa média percentual das horas são as bases de rateio para alocação dos custos indiretos a cada atividade do departamento fiscal, e foram calculadas sobre os regimes do Simples Nacional, Lucro Real e Lucro Presumido que utilizaram as horas divididas entre elas para o consumo total de horas por mês. Portando, será a base total das horas do departamento para o devido rateio em cada atividade e evidenciado detalhadamente na Tabela 7 os valores correspondentes atribuídos entre elas.

Tabela 7 - Rateio dos custos indiretos por atividades do departamento fiscal

\begin{tabular}{|c|c|c|c|c|c|c|c|c|c|c|}
\hline ATIVIDADE & 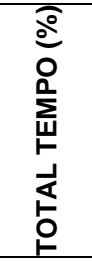 & 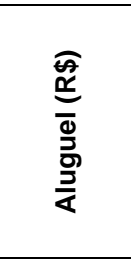 & 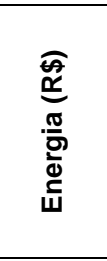 & 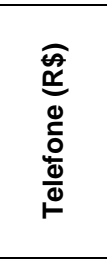 & 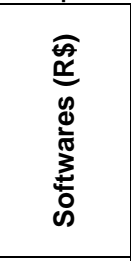 & 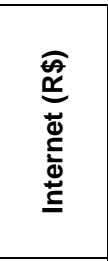 & 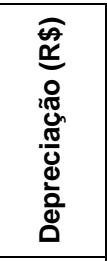 & 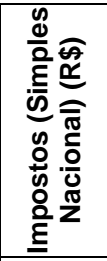 & 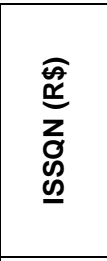 & 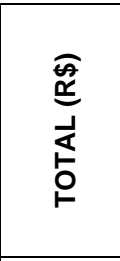 \\
\hline $\begin{array}{l}\text { EFETUAR } \\
\text { LANÇAMENTO DE } \\
\text { ENTRADAS E SAÍDAS }\end{array}$ & $98 \%$ & $1.255,46$ & 796,15 & 153,11 & $1.775,87$ & 121,87 & 114,83 & 312,34 & 180,66 & $4.710,29$ \\
\hline $\begin{array}{l}\text { APURAÇÃO DE } \\
\text { IMPOSTOS }\end{array}$ & $1 \%$ & 11,86 & 7,52 & 1,45 & 16,78 & 1,15 & 1,09 & 2,95 & 1,71 & 44,51 \\
\hline $\begin{array}{l}\text { TRANSMISSÃO DE } \\
\text { EFD - FISCAL E } \\
\text { CONTRIBUIÇÕES/LIV } \\
\text { ROS FISCAIS }\end{array}$ & $1 \%$ & 14,02 & 8,89 & 1,71 & 19,83 & 1,36 & 1,28 & 3,49 & 2,02 & 52,61 \\
\hline TOTAL & $100 \%$ & $1.281,35$ & 812,56 & 156,26 & $1.812,49$ & 124,38 & 117,20 & 318,77 & 184,39 & $4.807,41$ \\
\hline
\end{tabular}

Fonte: Dados da pesquisa, 2019.

Os totais dos custos indiretos rateados às atividades do departamento fiscal totalizaram o valor auferido conforme a Tabela 4 com valor total de $R \$ 4.807,41$ de recursos consumidos em todas as atividades do departamento fiscal e utilizando as horas mensais pela média percentual calculada sobre as horas totais do departamento.

A Tabela 8 apresenta a média percentual das horas totais para cada atividade do departamento contábil para a atribuição dos custos indiretos anteriormente 
identificados por meio de rastreamento que é o resultado do cálculo da média das horas mensais totais do departamento.

Tabela 8 - Média percentual do tempo utilizado no departamento contábil por atividades

\begin{tabular}{|c|c|}
\hline ATIVIDADES & \% TOTAL DO TEMPO \\
\hline $\begin{array}{lllll}\text { BAIXA DE } & \text { NOTAS } & \text { FISCAIS } & \text { E } & \text { LANÇAMENTOS } \\
\text { CONTÁBEIS } & & & & \end{array}$ & $35 \%$ \\
\hline CONCILIAÇÕES CONTÁBEIS E FISCAIS & $5 \%$ \\
\hline $\begin{array}{l}\text { APURAÇÃO E TRANSMISSÃO DE SPED ECF, ECD - } \\
\text { LIVRO DIÁRIO/RAZÃO }\end{array}$ & $60 \%$ \\
\hline TOTAL & $100 \%$ \\
\hline
\end{tabular}

Fonte: Dados da pesquisa, 2019.

Conforme tabela anterior, a atividade com maior média de ocupação do tempo no departamento contábil é atribuída às atividades de apuração e transmissão de SPED ECF, ECD e impressão de livros contábeis para o fechamento dos resultados dos clientes. São atividades com maiores necessidades de implementação técnica e foi coletada por meio de rastreamento a demanda com base no tempo para a correta alocação dos custos, principalmente os custos indiretos, que serão atribuídos às atividades na Tabela 9.

Tabela 9 - Rateio dos custos indiretos por atividades do departamento contábil

\begin{tabular}{|c|c|c|c|c|c|c|c|c|c|c|}
\hline ATIVIDADE & 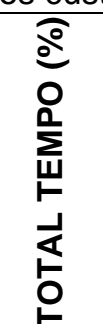 & 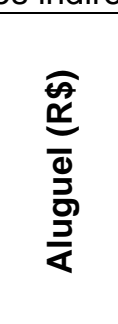 & 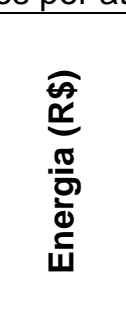 & 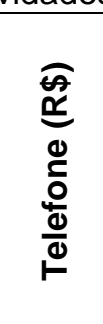 & 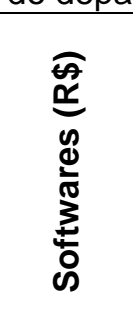 &  & 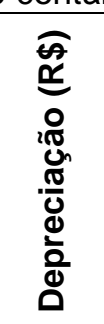 & 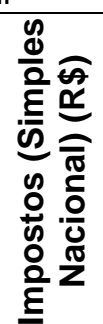 & 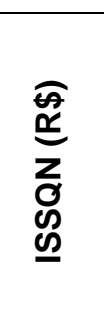 & $\begin{array}{l}\stackrel{1}{\leftarrow} \\
\stackrel{5}{\circ}\end{array}$ \\
\hline $\begin{array}{l}\text { BAIXA DE } \\
\text { NOTAS FISCAIS } \\
\text { E } \\
\text { LANÇAMENTOS } \\
\text { CONTÁBEIS }\end{array}$ & $34 \%$ & 103,61 & 65,71 & 12,64 & 146,56 & 10,06 & 9,48 & 25,78 & 14,91 & 388,74 \\
\hline $\begin{array}{l}\text { CONCILIAÇÕES } \\
\text { CONTÁBEIS E } \\
\text { FISCAIS }\end{array}$ & $5 \%$ & 15,62 & 9,90 & 1,90 & 22,09 & 1,52 & 1,43 & 3,89 & 2,25 & 58,60 \\
\hline $\begin{array}{l}\text { APURAÇÃO E } \\
\text { TRANSMISSÃO } \\
\text { DE SPED ECF, } \\
\text { ECD - LIVRO } \\
\text { DIÁRIO/RAZÃO }\end{array}$ & $60 \%$ & 182,47 & 115,71 & 22,25 & 258,10 & 17,71 & 16,69 & 45,39 & 26,26 & 684,59 \\
\hline TOTAL & $100 \%$ & 301,70 & 191,32 & 36,79 & 426,76 & 29,29 & 27,59 & 75,06 & 43,42 & $1.131,93$ \\
\hline
\end{tabular}

Fonte: Dados da pesquisa, 2019. 
A Tabela 9, assim como a Tabela 6 e Tabela 8, apresenta a média percentual para o departamento pessoal das suas atividades relevantes onde os recursos são consumidos mensalmente. Elas são a base para a alocação dos custos indiretos em cada atividade devido à representatividade das horas totais.

Tabela 10 - Média percentual do tempo utilizado no departamento pessoal por atividades

\begin{tabular}{l|c}
\multicolumn{1}{c|}{ ATIVIDADES } & \% TOTAL DO TEMPO \\
\hline CÁLCULO - FOLHA DE PAGAMENTO & $10 \%$ \\
ADMISSÕES/RECISÕES/FÉRIAS & $14 \%$ \\
RAIS/CAGED/DIRF/IR & $55 \%$ \\
AFASTAMENTOS INSS & $10 \%$ \\
SEFIP/GUIAS/RECÁLCULOS (INSS, FGTS, IR) & $11 \%$ \\
\hline \multicolumn{1}{c|}{ TOTAL } & $\mathbf{1 0 0 \%}$ \\
\hline
\end{tabular}

Fonte: Dados da pesquisa, 2019.

A Tabela 10 é a base para o rateio dos custos indiretos para cada atividade do departamento pessoal e apresenta os valores totais atribuídos para a realização do trabalho. A atividade com maior representatividade do tempo foi o registro da rais/caged/dirf/IR, pois o procedimento dos registros e conferências são realizadas por 12 meses e são revisados minuciosamente para cada cliente da organização contábil.

Estes cálculos de atribuição dos custos indiretos serão demonstrados na Tabela 11, com os custos alocados a cada atividade do departamento aplicando se as bases correspondentes sobre o valor total a distribuir entre elas como mostra a Tabela 4.

Tabela 11 - Rateio dos custos indiretos por atividades do departamento pessoal

\begin{tabular}{|c|c|c|c|c|c|c|c|c|c|c|}
\hline ATIVIDADE & 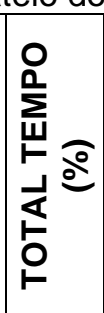 & 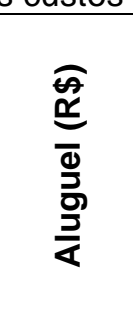 & 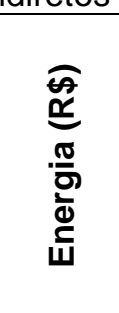 & 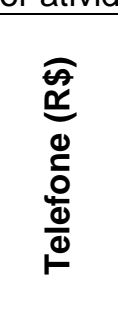 & 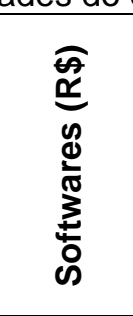 & 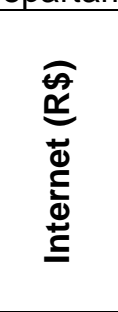 & 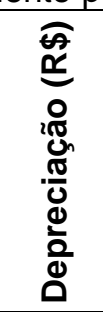 & 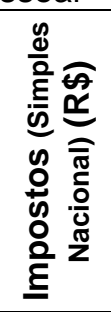 & 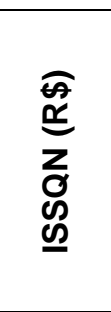 & $\frac{1}{5}$ \\
\hline $\begin{array}{l}\text { CÁLCULO } \\
\text { FOLHA DE } \\
\text { PAGAMENTO }\end{array}$ & $10 \%$ & 28,26 & 17,92 & 3,45 & 39,97 & 2,74 & 2,58 & 7,03 & 4,07 & 106,02 \\
\hline $\begin{array}{l}\text { ADMISSÕ̃ES/R } \\
\text { ECISÕES/FÉRI } \\
\text { AS }\end{array}$ & $14 \%$ & 39,70 & 25,18 & 4,84 & 56,16 & 3,85 & 3,63 & 9,88 & 5,71 & 148,96 \\
\hline $\begin{array}{l}\text { RAIS/CAGED/ } \\
\text { DIRF/IR }\end{array}$ & $55 \%$ & 155,95 & 98,90 & 19,02 & 220,59 & 15,14 & 14,26 & 38,80 & 22,44 & 585,10 \\
\hline AFASTAMENT & $10 \%$ & 28,26 & 17,92 & 3,45 & 39,97 & 2,74 & 2,58 & 7,03 & 4,07 & 106,02 \\
\hline
\end{tabular}




\begin{tabular}{|l|c|c|c|c|c|c|c|c|c|c|} 
OS INSS & & & & & & & & & & \\
\hline $\begin{array}{l}\text { SEFIP/GUIAS/ } \\
\text { RECÁLCULOS } \\
\text { (INSS, FGTS, } \\
\text { IR) }\end{array}$ & $11 \%$ & 31,12 & 19,73 & 3,79 & 44,02 & 3,02 & 2,85 & 7,74 & 4,48 & 116,75 \\
\hline \multicolumn{1}{|c|}{ TOTAL } & $\begin{array}{c}\mathbf{1 0 0} \\
\%\end{array}$ & $\mathbf{2 8 3 , 2 9}$ & $\mathbf{1 7 9 , 6 4}$ & $\mathbf{3 4 , 5 5}$ & $\mathbf{4 0 0 , 7 1}$ & $\mathbf{2 7 , 5 0}$ & $\mathbf{2 5 , 9 1}$ & $\mathbf{7 0 , 4 8}$ & $\mathbf{4 0 , 7 7}$ & $\mathbf{1 . 0 6 2 , 8 4}$ \\
\hline
\end{tabular}

Fonte: Dados da pesquisa, 2019.

A Tabela 12 apresenta a média percentual das horas totais do departamento financeiro, para execução do trabalho. Os cálculos foram realizados com base nas horas totais auferidas anteriormente para cada departamento e seus respectivos regimes tributários.

Tabela 12 - Média percentual do tempo utilizado no departamento financeiro por atividades

\begin{tabular}{l|c}
\multicolumn{1}{c|}{ ATIVIDADES } & \% TOTAL DO TEMPO \\
\hline CONTAS A PAGAR & $5 \%$ \\
CONTAS A RECEBER & $6 \%$ \\
CONTROLES BANCÁRIOS & $86 \%$ \\
COBRANÇA A CLIENTES & $3 \%$ \\
\hline \multicolumn{1}{c}{ TOTAL } & $\mathbf{1 0 0 \%}$ \\
\hline
\end{tabular}

Fonte: Dados da pesquisa, 2019.

A Tabela 12 é a base para o rateio dos custos indiretos das atividades executadas pelo departamento financeiro, e como mostra a Tabela 13 apresenta 0 valor total de custos indiretos rateados em todas as atividades de $R \$ 689,07$ e 0 aluguel apresentando o maior custo no departamento.

Tabela 13 - Rateio dos custos indiretos por atividades do departamento financeiro

\begin{tabular}{|c|c|c|c|c|c|c|c|c|c|c|}
\hline ATIVIDADE & $\begin{array}{l}\widehat{o} \\
o \\
0 \\
\frac{0}{4} \\
\frac{1}{5} \\
\frac{1}{6} \\
\frac{0}{1}\end{array}$ & 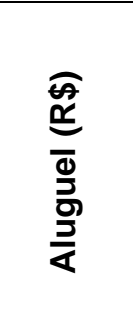 & 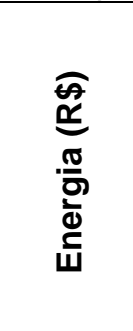 & 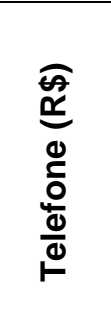 & 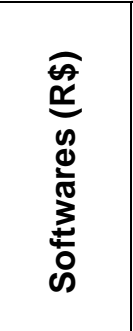 & 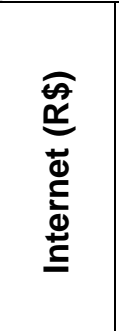 & 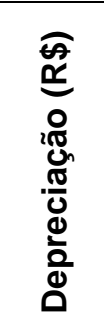 & 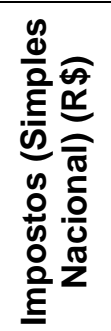 & 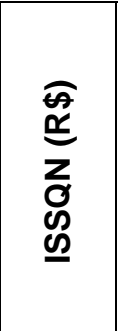 & 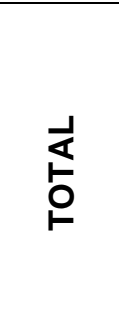 \\
\hline $\begin{array}{l}\text { CONTAS A } \\
\text { PAGAR }\end{array}$ & $5 \%$ & 8,81 & 5,59 & 1,07 & 12,46 & 0,86 & 0,81 & 2,19 & 1,27 & 33,06 \\
\hline $\begin{array}{l}\text { CONTAS A } \\
\text { RECEBER }\end{array}$ & $6 \%$ & 11,83 & 7,50 & 1,44 & 16,73 & 1,15 & 1,08 & 2,94 & 1,70 & 44,37 \\
\hline $\begin{array}{l}\text { CONTROLES } \\
\text { BANCÁRIOS }\end{array}$ & $86 \%$ & 158,62 & 100,59 & 19,34 & 224,37 & 15,40 & 14,51 & 39,46 & 22,83 & 595,11 \\
\hline
\end{tabular}




\begin{tabular}{|c|c|c|c|c|c|c|c|c|c|c|} 
COBRANÇA & $2 \%$ & 4,41 & 2,79 & 0,54 & 6,23 & 0,43 & 0,40 & 1,10 & 0,63 & 16,53 \\
A CLIENTES & $2 \%$ & & & & & & & \\
\hline TOTAL & $\mathbf{1 0 0} \%$ & $\mathbf{1 8 3 , 6 6}$ & $\mathbf{1 1 6 , 4 7}$ & $\mathbf{2 2 , 4 0}$ & $\mathbf{2 5 9 , 7 9}$ & $\mathbf{1 7 , 8 3}$ & $\mathbf{1 6 , 8 0}$ & $\mathbf{4 5 , 6 9}$ & $\mathbf{2 6 , 4 3}$ & $\mathbf{6 8 9 , 0 7}$ \\
\hline
\end{tabular}

Fonte: Dados da pesquisa, 2019.

Os rateios dos custos indiretos utilizando este rastreamento por atividades de cada departamento tem o objetivo de direcionar corretamente os custos a cada atividade que irá consumi-la com o método $A B C$ evitando distorções ou arbitrariedade dos custos aos departamentos.

A confiabilidade na apuração dos custos totais atinge sua totalidade, considerando que os custos diretos e indiretos estão devidamente alocados nas atividades relevantes e os departamentos presentes no escritório contábil em estudo, o próximo passo é apresentar os custos totais conforme o método $A B C$ a cada departamento rastreado neste estudo.

\subsubsection{Custos totais aplicados ao método $A B C$}

Após todo o processo de rastreamento dos centros de custos do escritório contábil, levantamento dos custos diretos e indiretos mensais, aferição das atividades relevantes, cálculos para encontrar a base de rateio dos custos e que o escritório em estudo está dividido em departamento fiscal, contábil, pessoal e financeiro e atribuição dos custos às suas atividades.

A Tabela 14 irá apresentar os custos totais a cada departamento com seus custos diretos e indiretos alocados, formando assim o custo total pelo método $A B C$ por departamento e pelos clientes do regime do Simples Nacional, Lucro Real e Lucro Presumido. Foram calculados utilizando as horas totais dos clientes como base para o rateio dos custos diretos e indiretos evidenciado no Quadro 3 para o departamento fiscal.

Tabela 14 - Custos totais do departamento fiscal conforme ABC

\begin{tabular}{l|rr|rr|rr|rr}
\hline $\begin{array}{c}\text { DEPARTAMENTO } \\
\text { FISCAL }\end{array}$ & \multicolumn{2}{c|}{$\begin{array}{c}\text { SIMPLES } \\
\text { NACIONAL }\end{array}$} & \multicolumn{2}{c|}{$\begin{array}{c}\text { LUCRO } \\
\text { PRESUMIDO }\end{array}$} & \multicolumn{2}{c|}{ LUCRO REAL } & \multicolumn{2}{c}{$\begin{array}{c}\text { CUSTO TOTAL } \\
\text { ABC }\end{array}$} \\
\hline $\mathrm{MOD}$ & $\mathrm{R} \$$ & $5.232,47$ & $\mathrm{R} \$$ & $3.924,35$ & $\mathrm{R} \$$ & $1.308,12$ & $\mathrm{R} \$$ & $10.464,93$ \\
\hline Aluguel & $\mathrm{R} \$$ & 640,68 & $\mathrm{R} \$$ & 480,51 & $\mathrm{R} \$$ & 160,17 & $\mathrm{R} \$$ & $1.281,35$ \\
\hline Energia & $\mathrm{R} \$$ & 406,28 & $\mathrm{R} \$$ & 304,71 & $\mathrm{R} \$$ & 101,57 & $\mathrm{R} \$$ & 812,56 \\
\hline Telefone & $\mathrm{R} \$$ & 78,13 & $\mathrm{R} \$$ & 58,60 & $\mathrm{R} \$$ & 19,53 & $\mathrm{R} \$$ & 156,26 \\
\hline Softwares & $\mathrm{R} \$$ & 906,24 & $\mathrm{R} \$$ & 679,68 & $\mathrm{R} \$$ & 226,56 & $\mathrm{R} \$$ & $1.812,49$ \\
\hline Internet & $\mathrm{R} \$$ & 62,19 & $\mathrm{R} \$$ & 46,64 & $\mathrm{R} \$$ & 15,55 & $\mathrm{R} \$$ & 124,38 \\
\hline
\end{tabular}




\begin{tabular}{l|rr|rr|rr|rr}
$\begin{array}{l}\text { Depreciação- } \\
\text { Computadores }\end{array}$ & $\mathrm{R} \$$ & 58,60 & $\mathrm{R} \$$ & 43,95 & $\mathrm{R} \$$ & 14,65 & $\mathrm{R} \$$ & 117,20 \\
\hline $\begin{array}{l}\text { Impostos (Simples } \\
\text { Nacional) }\end{array}$ & $\mathrm{R} \$$ & 159,39 & $\mathrm{R} \$$ & 119,54 & $\mathrm{R} \$$ & 39,85 & $\mathrm{R} \$$ & 318,77 \\
\hline ISSQN & $\mathrm{R} \$$ & 92,19 & $\mathrm{R} \$$ & 69,15 & $\mathrm{R} \$$ & 23,05 & $\mathrm{R} \$$ & 184,39 \\
\hline \multicolumn{1}{c|}{ TOTAL } & $\mathbf{R} \$$ & $\mathbf{7 . 6 3 6 , 1 7}$ & $\mathbf{R} \$$ & $\mathbf{5 . 7 2 7 , 1 3}$ & $\mathbf{R} \$$ & $\mathbf{1 . 9 0 9 , 0 4}$ & $\mathbf{R} \$$ & $\mathbf{1 5 . 2 7 2 , 3 4}$ \\
\hline
\end{tabular}

Fonte: Dados da pesquisa, 2019.

O departamento fiscal apresentou um custo total de $\mathrm{R} \$ 15.272,34$ com base na tabela acima, somando os custos diretos e indiretos para a prestação dos serviços contábeis de todos os clientes. Com a utilização do ABC, nota-se que os clientes enquadrados no regime do Simples Nacional, apresenta o maior valor de custo atribuído entre todos os outros regimes do departamento fiscal.

A Tabela 15 apresenta os custos totais e as atribuições feitas anteriormente ao departamento contábil para cada cliente, assim como na Tabela 14.

Tabela 15 - Custos totais do departamento contábil conforme ABC

\begin{tabular}{|c|c|c|c|c|c|c|c|c|}
\hline \multirow{2}{*}{$\begin{array}{c}\begin{array}{c}\text { DEPARTAMENTO } \\
\text { CONTÁBIL }\end{array} \\
\text { MOD } \\
\end{array}$} & \multicolumn{2}{|c|}{$\begin{array}{l}\text { SIMPLES } \\
\text { NACIONAL }\end{array}$} & \multicolumn{2}{|c|}{$\begin{array}{c}\text { LUCRO } \\
\text { PRESUMIDO }\end{array}$} & \multicolumn{2}{|c|}{ LUCRO REAL } & \multirow{2}{*}{\multicolumn{2}{|c|}{$\begin{array}{c}\text { CUSTO } \\
\text { TOTAL ABC } \\
\mathrm{R} \$ 2.464,02\end{array}$}} \\
\hline & $\mathrm{R} \$$ & $1.232,01$ & $\mathrm{R} \$$ & 924,01 & $\mathrm{R} \$$ & 308,00 & & \\
\hline Aluguel & $\mathrm{R} \$$ & 150,85 & $\mathrm{R} \$$ & 113,14 & $\mathrm{R} \$$ & 37,71 & $\mathrm{R} \$$ & 301,70 \\
\hline Energia & $\mathrm{R} \$$ & 95,66 & $\mathrm{R} \$$ & 71,75 & $\mathrm{R} \$$ & 23,92 & $\mathrm{R} \$$ & 191,32 \\
\hline Telefone & $\mathrm{R} \$$ & 18,40 & $\mathrm{R} \$$ & 13,80 & $\mathrm{R} \$$ & 4,60 & $\mathrm{R} \$$ & 36,79 \\
\hline Softwares & $R \$$ & 213,38 & $\mathrm{R} \$$ & 160,03 & $\mathrm{R} \$$ & 53,34 & $\mathrm{R} \$$ & 426,76 \\
\hline Internet & $\mathrm{R} \$$ & 14,64 & $\mathrm{R} \$$ & 10,98 & $\mathrm{R} \$$ & 3,66 & $\mathrm{R} \$$ & 29,29 \\
\hline $\begin{array}{l}\text { Depreciação } \\
\text { Computadores }\end{array}$ & $\mathrm{R} \$$ & 13,80 & $\mathrm{R} \$$ & 10,35 & $\mathrm{R} \$$ & 3,45 & $\mathrm{R} \$$ & 27,59 \\
\hline Impostos & $\mathrm{R} \$$ & 37,53 & $\mathrm{R} \$$ & 28,15 & $\mathrm{R} \$$ & 9,38 & $\mathrm{R} \$$ & 75,06 \\
\hline ISSQN & $\mathrm{R} \$$ & 21,71 & $\mathrm{R} \$$ & 16,28 & $\mathrm{R} \$$ & 5,43 & $\mathrm{R} \$$ & 43,42 \\
\hline TOTAL & $\mathbf{R} \$$ & $1.797,97$ & $\mathbf{R} \$$ & $1.348,48$ & $\mathbf{R} \$$ & 449,49 & $\mathbf{R} \$$ & $.595,95$ \\
\hline
\end{tabular}

Fonte: Dados da pesquisa, 2019.

No departamento contábil observa-se que os custos totais ao final da aplicação do método são de $\mathrm{R} \$ 3.595,95$ e os custos atribuídos aos clientes do Simples Nacional também foram maiores como na Tabela 14 no total de $R \$$ $1.797,97$ e o menor custo atribuído foi para os cliente do Lucro Real com total de $\mathrm{R} \$$ 449,49 de custos totais ao mês.

A Tabela 16 apresenta o valor total dos custos atribuídos aos clientes dos regimes tributários já citados anteriormente para o departamento pessoal, os valores dos custos diretos e indiretos já foram apresentados anteriormente.

Tabela 16 - Custos totais do departamento pessoal conforme ABC 


\begin{tabular}{l|c|c|c|c}
\hline $\begin{array}{c}\text { DEPARTAMENTO } \\
\text { PESSOAL }\end{array}$ & $\begin{array}{c}\text { SIMPLES } \\
\text { NACIONAL }\end{array}$ & $\begin{array}{c}\text { LUCRO } \\
\text { PRESUMIDO }\end{array}$ & $\begin{array}{c}\text { LUCRO } \\
\text { REAL }\end{array}$ & $\begin{array}{c}\text { CUSTO TOTAL } \\
\text { ABC }\end{array}$ \\
\hline MOD & $\mathrm{R} \$ 1.156,82$ & $\mathrm{R} \$ 867,61$ & $\mathrm{R} \$ 289,20$ & $\mathrm{R} \$ 2.313,63$ \\
\hline Aluguel & $\mathrm{R} \$ 141,64$ & $\mathrm{R} \$ 106,23$ & $\mathrm{R} \$ 35,41$ & $\mathrm{R} \$ 283,29$ \\
\hline Energia & $\mathrm{R} \$ 89,82$ & $\mathrm{R} \$ 67,37$ & $\mathrm{R} \$ 22,46$ & $\mathrm{R} \$ 179,64$ \\
\hline Telefone & $\mathrm{R} \$ 17,27$ & $\mathrm{R} \$ 12,96$ & $\mathrm{R} \$ 4,32$ & $\mathrm{R} \$ 34,55$ \\
\hline Softwares & $\mathrm{R} \$ 200,36$ & $\mathrm{R} \$ 150,27$ & $\mathrm{R} \$ 50,09$ & $\mathrm{R} \$ 400,71$ \\
\hline Internet & $\mathrm{R} \$ 13,75$ & $\mathrm{R} \$ 10,31$ & $\mathrm{R} \$ 3,44$ & $\mathrm{R} \$ 27,50$ \\
\hline $\begin{array}{l}\text { Depreciação } \\
\text { Computadores }\end{array}$ & $\mathrm{R} \$ 12,96$ & $\mathrm{R} \$ 9,72$ & $\mathrm{R} \$ 3,24$ & $\mathrm{R} \$ 25,91$ \\
\hline Impostos (Simples & $\mathrm{R} \$ 35,24$ & $\mathrm{R} \$ 26,43$ & $\mathrm{R} \$ 8,81$ & $\mathrm{R} \$ 70,48$ \\
Nacional) & $\mathrm{R} \$ 20,38$ & $\mathrm{R} \$ 15,29$ & $\mathrm{R} \$ 5,10$ & $\mathrm{R} \$ 40,77$ \\
\hline ISSQN & $\mathbf{R} \$ \mathbf{1 . 6 8 8 , 2 4}$ & $\mathbf{R} \$ \mathbf{1 . 2 6 6 , 1 8}$ & $\mathbf{R} \$ \mathbf{4 2 2 , 0 6}$ & $\mathbf{R} \mathbf{3 . 3 7 6 , 4 7}$ \\
\hline \multicolumn{1}{c|}{ TOTAL } & & &
\end{tabular}

Fonte: Dados da pesquisa, 2019.

O departamento pessoal apresenta os custos totais após a aplicação do método ABC conforme a Tabela 16 no valor de $\mathrm{R} \$ 3.376,47$ e os custos atribuídos mais altos são para os clientes do Simples Nacional, com valor total de $R \$ 1.688,24$, Lucro Presumido custo total de $\mathrm{R} \$ 1.266,18$ e o de menor custo atribuído para cliente do Lucro Real de $\mathrm{R} \$ 422,06$.

$\mathrm{Na}$ Tabela 17 serão apresentados os custos totais do departamento financeiro ao aplicar o método ABC seguindo os critérios adotados para a Tabela 14, Tabela 15 e Tabela 16.

Tabela 17 - Custos totais do departamento financeiro conforme ABC

\begin{tabular}{l|rr|rr|rr|rr}
\hline $\begin{array}{l}\text { DEPARTAMENTO } \\
\text { FINANCEIRO }\end{array}$ & \multicolumn{2}{|c|}{$\begin{array}{c}\text { SIMPLES } \\
\text { NACIONAL }\end{array}$} & \multicolumn{2}{c|}{\begin{tabular}{c}
\multicolumn{2}{c|}{ PUCRO } \\
PRESUMIDO
\end{tabular}} & \multicolumn{2}{c|}{ LUCRO REAL } & \multicolumn{2}{c}{$\begin{array}{c}\text { CUSTO TOTAL } \\
\text { ABC }\end{array}$} \\
\hline MOD & $\mathrm{R} \$$ & 750,00 & $\mathrm{R} \$$ & 562,50 & $\mathrm{R} \$$ & 187,50 & $\mathrm{R} \$$ & $1.500,00$ \\
\hline Aluguel & $\mathrm{R} \$$ & 91,83 & $\mathrm{R} \$$ & 68,87 & $\mathrm{R} \$$ & 22,96 & $\mathrm{R} \$$ & 183,66 \\
\hline Energia & $\mathrm{R} \$$ & 58,23 & $\mathrm{R} \$$ & 43,68 & $\mathrm{R} \$$ & 14,56 & $\mathrm{R} \$$ & 116,47 \\
\hline Telefone & $\mathrm{R} \$$ & 11,20 & $\mathrm{R} \$$ & 8,40 & $\mathrm{R} \$$ & 2,80 & $\mathrm{R} \$$ & 22,40 \\
\hline Softwares & $\mathrm{R} \$$ & 129,90 & $\mathrm{R} \$$ & 97,42 & $\mathrm{R} \$$ & 32,47 & $\mathrm{R} \$$ & 259,79 \\
\hline Internet & $\mathrm{R} \$$ & 8,91 & $\mathrm{R} \$$ & 6,69 & $\mathrm{R} \$$ & 2,23 & $\mathrm{R} \$$ & 17,83 \\
\hline $\begin{array}{l}\text { Depreciação- } \\
\text { Computadores }\end{array}$ & $\mathrm{R} \$$ & 8,40 & $\mathrm{R} \$$ & 6,30 & $\mathrm{R} \$$ & 2,10 & $\mathrm{R} \$$ & 16,80 \\
\hline $\begin{array}{l}\text { Impostos (Simples } \\
\text { Nacional) }\end{array}$ & $\mathrm{R} \$$ & 22,85 & $\mathrm{R} \$$ & 17,13 & $\mathrm{R} \$$ & 5,71 & $\mathrm{R} \$$ & 45,69 \\
\hline ISSQN & $\mathrm{R} \$$ & 13,21 & $\mathrm{R} \$$ & 9,91 & $\mathrm{R} \$$ & 3,30 & $\mathrm{R} \$$ & 26,43 \\
\hline \multicolumn{1}{c|}{ TOTAL } & $\mathbf{R} \$$ & $\mathbf{1 . 0 9 4 , 5 4}$ & $\mathbf{R} \mathbf{8}$ & $\mathbf{8 2 0 , 9 0}$ & $\mathbf{R} \$$ & $\mathbf{2 7 3 , 6 3}$ & $\mathbf{R} \mathbf{2 . 1 8 9 , 0 7}$ \\
\hline Fon
\end{tabular}

Fonte: Dados da pesquisa, 2019. 
Os custos totais do departamento financeiro totalizaram $R \$ 2.189,07$, por ser um setor com o mesmo total de horas trabalhadas dos departamentos pessoal e contábil, porém e o departamento que apresenta nos cálculos anteriores a mão de obra e o rateio dos custos indiretos mais baixos para execução do trabalho mensal, por serem atividades com procedimentos mais automatizados em sistemas bancários e os controles dos fluxos de caixa interno da empresa contábil.

$\mathrm{Na}$ Tabela 18 apresenta o somatório dos custos totais calculado por meio do $A B C$ por departamentos e por regimes tributários dos clientes, como forma de mostrar qual é o departamento de maior custo e, após este procedimento, realizar a apuração dos resultados com base no valor mensal dos honorários praticados pela empresa contábil a cada regime tributário.

Tabela 18 - Custos totais por departamento conforme ABC

\begin{tabular}{|c|c|c|c|c|c|c|}
\hline DEPARTAMENTOS & & $\begin{array}{l}\text { IMPLES } \\
\text { CIONAL }\end{array}$ & PRE & $\begin{array}{l}\text { UCRO } \\
\text { SUMIDO }\end{array}$ & $\begin{array}{l}\text { LUCRO } \\
\text { REAL }\end{array}$ & $\begin{array}{l}\text { CUSTO } \\
\text { TOTAL }\end{array}$ \\
\hline DEPARTAMENTO FISCAL & $\mathrm{R} \$$ & $7.636,17$ & $\mathrm{R} \$$ & $5.727,13$ & $\mathrm{R} \$ 1.909,04$ & $R \$ 15.272,34$ \\
\hline $\begin{array}{l}\text { DEPARTAMENTO } \\
\text { CONTÁBIL }\end{array}$ & $\mathrm{R} \$$ & $1.797,97$ & $\mathrm{R} \$$ & $1.348,48$ & $\mathrm{R} \$ \quad 449,49$ & $\mathrm{R} \$ 3.595,95$ \\
\hline $\begin{array}{l}\text { DEPARTAMENTO } \\
\text { PESSOAL }\end{array}$ & $\mathrm{R} \$$ & $1.688,24$ & $\mathrm{R} \$$ & $1.266,18$ & $\mathrm{R} \$ 422,06$ & $\mathrm{R} \$ 3.376,47$ \\
\hline $\begin{array}{l}\text { DEPARTAMENTO } \\
\text { FINANCEIRO } \\
\end{array}$ & $\mathrm{R} \$$ & $1.094,54$ & $\mathrm{R} \$$ & 820,90 & $\mathrm{R} \$ 273,63$ & $\mathrm{R} \$ 2.189,07$ \\
\hline TOTAL & $\mathbf{R} \$$ & $12.216,92$ & $\mathbf{R} \$$ & $9.162,69$ & $R \$ 3.054,23$ & $\mathrm{R} \$ 24.433,83$ \\
\hline
\end{tabular}

Após a aplicação do método de custeio $A B C$ foram encontrados os custos totais por departamento, e os clientes do Simples Nacional são os que mais consomem recursos sobre os processos cotidiano do escritório contábil em estudo no valor total de $R \$ 12.216,92$ de custos totais. Os clientes do Lucro Presumido também apresentaram custos altos mensalmente, no valor total de $\mathrm{R} \$ 9.162,69$ chegando como conclusão que estes clientes demandam mais tempo para execução de suas atividades. O menor custo foi apresentado pelos clientes do Lucro Real no total de $\mathrm{R} \$ 3.054,23$ por ser representado pela menor quantidade de clientes.

\subsubsection{Demonstração do resultado}

Finalizando, após os procedimentos aplicados por meio do método $A B C$ e os custos totais mensurados aos departamentos com os devidos rateios dos custos 
diretos e indiretos às atividades apurados anteriormente, foram coletados os dados referentes aos honorários cobrados aos clientes por meio dos regimes tributários e multiplicando a quantidade de empresas constantes no quadro de cliente da organização e seus respectivos regimes.

O escritório contábil conta com 80 clientes enquadradas no regime do Simples Nacional e o valor unitário mensal cobrado para o cliente é de $R \$ 499,00$. Para os clientes do Lucro Presumido os serviços cobrados totalizam $\mathrm{R} \$ 1.500,00$ para os 10 clientes do escritório e para o Lucro real o total de $R \$ 3.000,00$ para o número de 2 clientes, todos cobrados mensalmente. $O$ resultado será demonstrado na Tabela 19.

Tabela 19 - Apuração dos resultados do escritório contábil

\begin{tabular}{ll|l|l|l|c}
\hline \multicolumn{1}{c|}{ DRE } & SIMPLES NACIONAL & $\begin{array}{c}\text { LUCRO } \\
\text { PRESUMIDO }\end{array}$ & LUCRO REAL & TOTAL \\
\hline $\begin{array}{l}\text { RECEITA } \\
\begin{array}{l}\text { PRESTAÇÃO } \\
\text { SERVIÇOS }\end{array}\end{array}$ & DE & $\mathrm{R} \$ 39.920,00$ & $\mathrm{R} \$ 15.000,00$ & $\mathrm{R} \$ 6.000,00$ & $\mathrm{R} \$ 60.920,00$ \\
\hline (-) CSP & $\mathrm{R} \$ 12.216,92$ & $\mathrm{R} \$ 9.162,69$ & $\mathrm{R} \$ 3.054,23$ & $\mathrm{R} \$ 24.433,83$ \\
\hline (=)LUCRO BRUTO & $\mathbf{R} \$ \mathbf{2 7 . 7 0 3 , 0 9}$ & $\mathbf{R} \mathbf{5 . 8 3 7 , 3 1}$ & $\mathbf{R} \mathbf{2 . 9 4 5 , 7 7}$ & $\mathbf{R} \mathbf{3} \mathbf{3 6 . 4 8 6 , 1 7}$ \\
\hline
\end{tabular}

Fonte: Dados da pesquisa, 2019.

O Lucro Bruto total dos serviços contábeis prestados aos clientes do escritório contábil é de $\mathrm{R} \$ 36.486,17$ após a aplicação do método de Custeio ABC considerando primordialmente o tempo que cada departamento gasto para a sua execução total. É possível verificar que os clientes do Simples Nacional apresentaram os maiores custos, porém apresentaram também os maiores lucros mensais para o escritório com total de $\mathrm{R} \$ 27.703,09$ ou $76 \%$ de representatividade no lucro total do mês.

É possível verificar que as empresas do Lucro Real e Presumido são as que possuem custos altos e o retorno em forma de lucro é baixo com representatividade mensal de $8 \%$ ou $R \$ 2.945,77$ e $16 \%$ ou $R \$ 5.837,31$ respectivamente.

A análise vertical dos itens acima foi mensurada por meio do cálculo sobre a representatividade do lucro bruto sobre as receitas de prestação de serviços, e a representatividade dos custos divididos pela receita bruta, demonstrados na tabela 20 e com base nos dados identificados na Tabela 19. 


\begin{tabular}{|l|c|c|c|}
\hline \multicolumn{1}{|c|}{ ANÁLISE VERTICAL (\%) } & $\begin{array}{c}\text { SIMPLES } \\
\text { NACIONAL }\end{array}$ & LUCRO PRESUMIDO & LUCRO REAL \\
\hline Custo $\times$ Receita & $31 \%$ & $61 \%$ & $51 \%$ \\
\hline Lucro $\times$ Receita & $69 \%$ & $39 \%$ & $49 \%$ \\
\hline
\end{tabular}

Fonte: Dados da pesquisa, 2019.

A tabela demonstra que para os custos do Simples Nacional representam $31 \%$ da receita bruta mensal para a organização contábil em estudo e que os lucros representam $69 \%$ da receita, podendo concluir que os resultados obtidos são satisfatórios para estes clientes. Já as empresas do Lucro Presumido e Real apresentam maior representatividade dos custos sobre a receita com $61 \%$ e $51 \%$ respectivamente e os lucros delas apresentam percentuais baixos, de $39 \%$ para o Lucro Presumido e 49\% para os clientes do Lucro real.

As empresas do Simples Nacional são mais lucrativas para a organização contábil em estudo, mais que as empresas do Lucro Presumido e Real que apresentaram maiores custos sobre suas operações.

\section{CONSIDERAÇÕES FINAIS}

Com o avanço da competitividade das organizações no mercado, como citado na presente pesquisa, a importância para as empresas na aquisição de métodos de custeio que disponibilizem informações mais precisas aumentou significativamente. O melhor desempenho aparece quando a oferta de informações para melhores tomadas de decisões é de qualidade extrema, sem margens de erros e esse fator é preponderante para que as organizações atuais tenham os melhores sistemas de custeio, que identifiquem com confiabilidade os custos em cada atividade que seja relevante para a organização em questão.

Neste contexto, o método de custeio empregado nesta pesquisa, juntamente com o escritório contábil de Lucas do Rio Verde objeto deste trabalho foi o (ABC) que é o método que apresenta mais detalhes sobre a organização, são divididas em centros de custos que consomem recursos e estes, às atividades relevantes de um departamento específico.

Após mapeamento dos processos base para aplicação do ABC, constatou-se que a empresa contábil em estudo não possuía forma alguma de apuração dos custos por cliente e os custos eram atribuídos de forma arbitrária para cada cliente. 
Os reajustes dos honorários eram feitos com base no salário mínimo vigente no país, devido a isso, verificou-se a necessidade de aplicação de um método de custeio com maior benefício para os resultados da empresa em estudo.

Com intuito de proporcionar ao escritório contábil em estudo a melhoria de desempenho que o método pode apontar sobre cada departamento, devido a identificação de quais departamentos internos consomem mais recursos, quais serão as representatividades de cada uma na composição da receita auferida pelos lucros obtidos, e a composição dos custos em relação a receita bruta.

Partindo das premissas para a implantação do método de custeio $A B C$, foram realizados os levantamentos dos custos totais mensais da empresa em estudo, quais são os departamentos que consomem as atividades, e essas atividades que geram custos para a prestação dos serviços aos clientes da empresa em estudo.

Ao identificar os centros de custos que consomem os recursos da empresa e o seu mapeamento em atividades da empresa contábil em estudo, por meio dos departamentos fiscal, contábil, pessoal e financeiro e a utilização de base para o rateio dos custos por meio das horas mensais (tempo) para cada cliente e contemplar os resultados sobre quais atividades apresenta o melhor desempenho.

Após a aplicação do custeio ABC na organização contábil em estudo, foram encontrados que os clientes enquadrados no Simples Nacional apresentaram os maiores desempenhos e maior lucratividade para a empresa contábil, logo atrás estão os clientes enquadrados no Lucro Presumido apresentando um desempenho satisfatório, mas ainda assim, menos lucrativo que os clientes do Simples Nacional. Os clientes do Lucro Real apresentaram um desempenho inferior a todos e os custos para a prestação dos serviços de seu alcance apresentaram altos índices percentuais sobre a sua receita bruta e baixa lucratividade.

A principal vantagem da aplicação do método de custeio $A B C$ no escritório contábil, foi apresentar uma alocação dos custos diretos e indiretos de forma confiável a cada departamento e suas atividades relevantes, podendo assim analisar quais setores podem ser melhorados para desempenhar maior lucratividade, e até reduzir custos de atividades com processos de maior valor.

Como desvantagem, os processos analisados nesta pesquisa podem ser aplicados somente na empresa contábil em estudo, pelo fato de apresentar estudo de caso específico aos dados coletados internamente na empresa. 
Finalizando, a título de recomendação para pesquisas futuras, verificar a possibilidade de implantação do método de custeio $A B C$ em todos os ramos de prestação de serviços, analisando sua viabilidade em todos os ramos de serviços presentes no mercado atual, sua necessidade em cada empresa, seus custos de implantação de todo o processo e as dificuldade em que as empresas possuem na mensuração dos seus custos. Outra recomendação, é que a implantação do processo seja feita anualmente para contemplar os custos de todo o ano para cada cliente e os referidos resultados sem delimitação do tempo.

\section{REFERÊNCIAS}

ATKINSON, Anthony A. et al. Contabilidade Gerencial. 3. ed. São Paulo: Atlas, 2011.

BERTI, Anélio; Contabilidade e Análise de Custos. 1. ed. (ano 2006). Curitiba: Juruá, 2009.

BERTI, Anélio; Contabilidade e Análise de Custos. 2. ed. (ano 2009). Curitiba: Juruá, 2010.

BEULKE, Rolando. Gestão de Custos. São Paulo: Saraiva, 2006.

BLOCHER, Edward J. [et al.]; Gestão estratégica de custos. 3 ed. São Paulo: McGraw-Hill, 2007.

BRASIL. Decreto n 9.580, De 22 de Novembro de 2018. Regulamento do Imposto sobre a Renda e Proventos de Qualquer Natureza. Brasília, DF, Nov. 2018.

Disponível em: <http://www.planalto.gov.br/ccivil_03/_Ato2015-

2018/2018/Decreto/D9580.htm\#art4 > Acesso em: 28 de maio de 2019.

Fontoura, Fernando Batista Bandeira da. Gestão de custos: uma visão integradora e prática dos métodos de custeio. São Paulo: Atlas, 2013. GIL, Antonio Carlos. Como elaborar projetos de pesquisa. 4. ed. São Paulo: Atlas, 2002.

Horngren, Charles T. Contabilidade de Custos, v. 1: uma abordagem gerencial. 11. ed. São Paulo: Prentice Hall, 2004.

MARTINS, Eliseu; Contabilidade de custos. 9. ed. São Paulo: Atlas, 2003. MARTINS, Eliseu; Contabilidade de custos. 10. ed. São Paulo: Atlas, 2010. MEGLIORINI, Evandir. Custos: análise e gestão. 3. ed. São Paulo: Pearson Education do Brasil Ltda, 2012. 
PADOVEZE, Clóvis Luís. Contabilidade gerencial: um enfoque em sistema de informação contábil. 7. ed. São Paulo: Atlas, 2010.

Souza, Marcos Antônio de; Diehl, Carlos Alberto. Gestão de custos: uma abordagem integrada entre contabilidade, engenharia e administração. São Paulo: Atlas, 2009.

MAUAD, Luiz Guilherme Azevedo; PAMPLONA, Edson de oliveira. O Custeio Abc em empresas de serviços: Características observadas na implantação em uma empresa do setor. IX Congresso Brasileiro de Custos - São Paulo, SP, Brasil, 13 a 15 de outubro de 2002. [Arquivo PDF]. Disponível em:<https://anaiscbc.emnuvens.com.br/anais/article/view/2636> Acesso em: 03 de novembro de 2019. 